\title{
El rey o el papa. La crisis de lealtades del alto clero español a través de la controversia de 1799 en la Rota de la nunciatura
}

The King or the Pope? An approach to the Spanish

Higher Clergy's Loyalty Crisis through the controversy

in the Nunciature's Rota Tribunal (1799)

\author{
Andoni ARTOLA RENEDO \\ Universidad del País Vasco \\ Institut d'Histoire de la Révolution Française. \\ andoni.artola@ehu.eus
}

\begin{abstract}
This paper examines the crisis in the longterm relationship model between the Spanish upper clergy, the Crown and the Papacy. Throughout the ancien régime, the high-ranking secular clergy divided its loyalty between two sovereign powers without any major problem. But this double loyalty underwent a crisis in the second half of the eighteenth century, aggravated by the French Revolution and the international political context. The controversy that arose between the members of the Spanish Rota tribunal concerning the royal decree of 1799, which ordered bishops and some royal courts to assume functions reserved to the Holy See, shows on a micro level the factors that led people to choose one loyalty over another.
\end{abstract}

Keywords: Spanish Nunciature; Rota tribunal; French Revolution; Upper Clergy; Ecclesiology; Prosopography.
Resumen: Este texto examina la crisis del marco de doble lealtad que, durante el Antiguo Régimen, había vinculado al alto clero simultáneamente a la Corona y a la Santa Sede. La aproximación al desequilibrio de esta fidelidad compartida se realiza desde el nivel micro, tomando como ejemplo la controversia que tuvo lugar en la Rota de la nunciatura de España como consecuencia del real decreto de 5 de septiembre de 1799, en virtud del cual los obispos y algunos tribunales regios ejercerían, durante la vacante de la silla pontificia ocasionada por la muerte de Pío VI, algunas facultades reservadas a la Santa Sede. El seguimiento detallado de las trayectorias previas de los participantes en la controversia explica, en buena medida, la postura eclesiológica que sostuvieron.

Palabras clave: Rota de la nunciatura; Revolución francesa; Alto Clero; Eclesiología; Prosopografía.

La vacante de la silla pontificia que siguió a la muerte de Pío VI en Valence, el 29 de agosto de 1799, creó una situación crítica para un alto clero español que se vería dividido al alterarse el equilibrio de lealtades compartidas entre dos poderes (pontificio y regio) en el cual se había movido con relativa comodidad hasta entonces. El 5 de septiembre de aquel año, Carlos IV expedía en Aranjuez un real decreto por el cual, ante la ocupación de Roma por las tropas francesas y la dispersión del colegio cardenalicio, unidas a lo agitado «de las circunstancias 
actuales de Europa» que dificultarían la elección de un nuevo papa en un tiempo razonable, disponía una serie de medidas para que el gobierno eclesiástico en sus dominios pudiera desarrollarse correctamente al margen de lo que ocurriera con una Santa Sede que, en aquel momento de incertitud, experimentaba el ciclo revolucionario francés como una auténtica empresa dirigida a su destrucción ${ }^{1}$.

En virtud del decreto los obispos deberían usar, de forma provisional, de una «plenitud de facultades» que se les suponía haber tenido en la «antigua disciplina de la Iglesia» para todo aquello que antes se gestionaba desde Roma. Se mencionaban, en particular, el otorgamiento de dispensas matrimoniales y la cuestión clave de la consagración de los obispos -que implicaba, ni más ni menos, prescindir de su confirmación por el papa-. El episcopado acudiría al Consejo de Castilla, de la misma manera que antes acudía a Roma, para la resolución de las dudas que pudieran surgir en aquella tesitura. No menos importante, los dos tribunales dependientes en última instancia de la Santa Sede (el de la Inquisición y el de la Rota de la nunciatura) continuarían funcionando bajo la sola autoridad del rey.

Este decreto sin precedentes no encerraba, al contrario de lo que quiso cierta historiografía, ningún proyecto cismático. Suponía, eso sí, la culminación de un proceso de acaparamiento del espacio eclesiástico por parte de la Corona durante el siglo que llegaba a su fin ${ }^{2}$. Se puede afirmar que el decreto se dirigía a obtener, aprovechando una situación extraordinaria que permitía llevar las argumentaciones de cada parte en conflicto hasta su extremo, futuras concesiones de la Santa Sede en favor del rey. Habría que añadir a esto las razones diplomáticas, particularmente la posibilidad de influir en la elección del nuevo pontífice, y las económicas, consistentes en la interrupción del flujo de caudales que anualmente salía hacia Roma en pago de dispensas matrimoniales ${ }^{3}$.

Las medidas adoptadas recogían, asimismo, algunos de los ideales de gobierno eclesiástico que a lo largo y ancho de la Europa católica se venían

1 Philippe BouTry, La tentative française de destruction du Saint-Siège (1789-1814), en Philippe LEVILLAIN (comp.), «Rome, l'unique objet de mon ressentiment». Regards critiques sur la Papauté, Roma, 2011, pp. 79-100.

2 En este sentido lo entendía ya en 1968, ante la interpretación dominante de su carácter «cismático», Marcelin DÉFOURNEAUX, Fansénisme et régalisme dans l'Espagne du XVIII siècle, en Caravelle: Cabiers du Monde Hispanique et lusobrésilien, 11 (1968), pp. 163-179 [p. 177].

3 El trabajo más completo sobre el tema sigue siendo el de Luis SIERRA NAVA, La reacción del episcopado español ante los decretos de matrimonios del Ministro Urquijo de 1799 a 1813, Bilbao, 1964. Véase también Rafael OlAECHEA, Las relaciones hispanorromanas en la segunda mitad del siglo XVIII. La agencia de preces, Zaragoza, 1965, pp. 581-591. 
oponiendo a la centralidad del poder pontificio en la sociedad eclesiástica ${ }^{4}$. Estas corrientes eclesiológicas, que constituían un movimiento centrífugo con respecto a la Santa Sede, tendían a atenuar la autoridad pontificia o a difuminarla en el conjunto de la Iglesia universal. El jansenismo dieciochesco (o jansenismos, como prefieren algunos autores dada la variedad de realidades que envolvía el vocablo) ${ }^{5}$, el episcopalismo o el richerismo tenían como común denominador su antirromanismo. En sus formulaciones ideales buscaban modificar la constitución eclesiástica mediante el retorno a las prácticas depuradas de una idealizada Iglesia primitiva, promoviendo el aumento de la capacidad de actuación de los obispos o el gobierno eclesiástico colegiado. Convergían, en ese objetivo común, con los poderes regios de la Europa católica, para cuyas aspiraciones jurisdiccionalistas (léase regalismo en España, galicanismo en Francia o josefinismo en Austria) su argumentario resultaba de evidente interés justificativo.

Esta dinámica centrífuga corría paralela a otra centrípeta, la de una autoridad pontificia que insistía, desde el siglo XVII, en la afirmación progresiva de una única soberanía apostólica, poseedora de la plenitud de funciones legislativa, disciplinar y magisterial en el seno de la sociedad eclesiástica. Esta tendencia alcanzaba un hito en su progresión a la altura de 1794 con la redacción de la bula Auctorem fidei, condenatoria de las actas del sínodo de Pistoya, en la que Philippe Boutry observa los componentes esenciales de la intransigencia católica que llegaría a su plenitud durante el siglo XIX ${ }^{6}$. La idea nuclear de la bula, la de una sociedad eclesiástica en cuyo centro se situara la autoridad magisterial del

4 Para una síntesis de estas corrientes, Ulrich D. LEHNER, Catholic Enlightenment. The Forgotten History of a Global Movement, New York, 2016; Jeffrey BurSON y Ulrich D. LEHNER, Enlightenment and Catholicism in Europe. A Transnational History, Notre Dame, 2014; Sylvio DE FRANCESCHI (comp.), Le pontife et l'erreur. Anti-infaillibilisme catholique et romanité ecclésiale aux temps posttridentins (XVII $\left.-X X^{e}\right)$, Lyon, 2010; Carlo FANTAPPIÈ, Le dottrine teologiche e canonistiche sulla costituzione e sulla riforma della Chiesa nell Settecento, en Anales de la Real Sociedad Económica de Valencia, CXII (2002), pp. 739-769; Juan María LABOA, La estructura eclesiástica en la época moderna, en Ricardo García Villoslada, Bernardino LlorCa y Juan María LabOA, Historia de la Iglesia Católica, Madrid, 1991, t. IV, pp. 193-249; Giuseppe ALBERIGO, Lo sviluppo della dottrina sui poteri nella Chiesa universale. Momenti essenziali tra il XVI e il XIX secolo, Roma/Freiburg/Basel/Barcelona/ Wien, 1964.

5 Monique COTtret, Fansénismes et Lumières. Pour un autre XVIII siècle, Paris, 1998.

6 Philippe BOUTRY, Tradition et autorité dans la théologie catholique au tournant des XVIIIe et XIX siècles. La Bulle Auctorem fidei (28 août 1794), en Jean-Dominique DURAND (dir.), Histoire et théologie, Paris, 1994, pp. 59-82; Bruno NEVEU, Juge suprême et docteur infaillible: le pontificat romain de la bulle «In eminenti» (1643) à la bulle «Auctorem fidei» (1794), en Mélanges de l'Ecole française de Rome. Moyen-Age, Temps modernes, 1981, t. 93/1 (1981), pp. 215-275. 
pontífice romano, se había visto acelerada en su desarrollo por la irrupción del ciclo revolucionario ${ }^{7}$.

El episodio de 1799 condensa la serie de tensiones eclesiológicas que recorrieron el siglo XVIII. Resulta ser un excelente observatorio analítico de la radicalización de posturas que se produjo durante las últimas décadas de la centuria en torno a la estructuración interna de la sociedad eclesiástica. La diversidad de concepciones sobre la autoridad, la jerarquía o el gobierno eclesiástico fue acumulándose en dos extremos. En esta situación, el alto clero se veía obligado a escoger entre uno de los polos fidelizadores entre los que había oscilado previamente, reaccionando de una manera concreta, clara y precisa a las medidas contenidas en el decreto de 5 de septiembre de 1799.

Si las características generales de la evolución eclesiológica descrita son bien conocidas apenas comenzamos a descubrir las razones que movían a la adscripción a una u otra de las dos grandes opciones que se estaban perfilando con cada vez mayor claridad a finales del siglo XVIII. En este trabajo nos aproximamos a ese marco general desde el debate que, en torno a la jurisdicción del nuncio apostólico, tuvo lugar como consecuencia del decreto de 5 de septiembre de 1799 en el (escasamente estudiado) ${ }^{8}$ tribunal de la Rota de la nunciatura.

Comenzamos con una puesta en contexto de la creación del tribunal en 1771. En segundo lugar, repasamos brevemente los argumentos eclesiológicos que las partes en conflicto manejaron en favor o en contra el poder pontificio. Pasamos después a exponer las características del personal de la Rota en la última década del siglo, así como la alta competencia que rodeaba la obtención de sus plazas. Por último, analizamos con detalle la trayectoria de los implicados en el conflicto. El reducido número de personas que componían el tribunal permitirá captar en detalle los factores que animaron el posicionamiento del alto clero en esta crítica coyuntura.

7 La Revolución francesa no habría provocado tanto la ruptura con las controversias del pasado reciente, sino la intensificación de éstas. Gérard PELLETIER, Rome et la Révolution française: la théologie et la politique du Saint-Siège devant la Révolution française, Roma, 2004; Marina CAFFIERO, Le problème religieux, en Annales historiques de la Révolution française, 4 (2003), pp. 139-154; Sylvio DE FRANCESCHI, L'autorité pontificale face au legs de l'antirromanisme catholique et régaliste des Lumières: réminiscences doctrinales de Bellarmin et de Suárez dans la théologie politique et l'ecclésiologie catholiques de la mi-XVIIIème à la mi-XIXème, en Archivum Historiae Pontificiae, 38 (2000), pp. 119-163.

8 Los dos últimos trabajos que conocemos tratan escasamente de la Rota durante el siglo XVIII, retomando para ello los trabajos anteriormente publicados sobre el tribunal. Joaquín MANTECÓN SANCHO, La restauración del Tribunal de la Rota de la Nunciatura en 1947, Santander, 2007, pp. $15-$ 26; Manuel PuENTE BRUNKe, La naturaleza jurídica de la Rota española, en Cuadernos doctorales: derecho canónico, derecho eclesiástico del Estado, 19 (2002), pp. 233-312. 


\section{LA ROTA DE LA NUNCIATURA EN EL CONTEXTO LA POLÍTICA ECLESIÁSTICA DE LA SEGUNDA MITAD DEL SIGLO XVIII}

\section{La creación del tribunal, una aspiración regalista}

El tribunal de la Rota de la nunciatura de las Españas fue creado por el breve Administrandae iustitiae zelus en marzo de 1771. Venía a sustituir al institucionalmente poco definido tribunal del nuncio, formado por éste mediante las facultades pontificias delegadas en su nombramiento, por un tribunal establemente constituido. El antiguo tribunal recibía la jurisdicción contenciosa del nuncio, que era subdelegada en un auditor de su elección o en los jueces in curia que nombraba él mismo, en quienes también subdelegaba las facultades de legado pontificio -en principio extraordinarias, pero que se otorgaban regularmente a los nuncios en España-. En esta configuración, que otorgaba al nuncio una importante libertad de actuación e intervención en la resolución de causas (perjudicando en ocasiones la jurisdicción ordinaria de los obispos), el tribunal no tuvo ningún reconocimiento institucional en España hasta el concordato de 1737, en el que se mencionaba explícitamente su existencia9.

La creación de la Rota comportaba la separación de las atribuciones jurisdiccionales del nuncio y las propias del tribunal. El nuncio debería, en adelante, someter las causas que le llegaran a los jueces de la Rota, pero no mediante subdelegación de sus facultades sino por una comisión meramente procedimental. No resolvería ya las causas personalmente ni podría subdelegar sus facultades.

Desde entonces sería la Rota la que, como tribunal colegiado, juzgaría las causas. Los seis jueces auditores de que se compondría, organizados en dos turnos a la manera de la Rota romana, conocerían en primera instancia las causas del clero regular y demás exentos directamente dependientes de la Santa Sede y, en apelación, las sentencias que hubieran dado los obispos o arzobispos. Entenderían de diezmos, de causas matrimoniales, beneficiales, de disciplina, de los votos de profesión religiosa o de las diferencias habidas en el capítulo provincial de una orden, entre otros asuntos. Con ello, se materializaba una aspiración que, desde el siglo XVI al XVIII, había aparecido de manera intermitente entre las reclamaciones de la Corona a la Santa Sede: la formación de

9 Novísima recopilación de las leyes de España, Madrid, 1805, libro II, título V, ley I. Manuel PUENTE, La naturaleza... [ver n. 8], pp. 237-270. 
una instancia en la que se resolvieran las causas eclesiásticas sin que salieran de España ${ }^{10}$.

En algunos sectores romanos la formación del tribunal de la Rota fue interpretada como una considerable reducción de la capacidad de actuación del poder pontificio ${ }^{11}$. No es de extrañar, si se tiene en cuenta que los cambios en materia jurisdiccional implican modificaciones en las relaciones de poder. Las consecuencias que podían tener los nuevos procedimientos en la formación de vínculos de lealtad de Roma en España podían ser significativas. Benedicto XIV las exponía claramente cuando afirmaba en carta al nuncio, algunos años antes, que convenía fomentar los recursos a la Santa Sede ya que éstos ayudaban a conservar la unión de los fieles con su cabeza ${ }^{12}$. En la misma línea, en 1750, ante la propuesta del fiscal del Consejo de Castilla de crear un tribunal eclesiástico en perjuicio del nuncio, éste protestaba enérgicamente argumentando que el papa, como primado, era por definición superior a todos los fieles, obispos, o prelados del orbe católico. Por lo tanto (deducía de este principio) todos los fieles tenían derecho de recurrir a la Santa Sede, lo cual no se podía impedir sin faltar a la obediencia debida al pontífice romano ${ }^{13}$.

Lo que interesa subrayar por ahora es que la creación del tribunal se produjo en un momento de notoria hegemonía de la Monarquía sobre lo eclesiástico. Este fenómeno, paralelo a la expansión del poder regio en otros ámbitos (administración del territorio, fiscalidad, gobierno municipal, ejército, etc.), experimentaría un importante progreso en las fechas previas a la creación de la $\operatorname{Rota}^{14}$. La decisión definitiva de Carlos III de negociar la reforma completa del tribunal del nuncio data de 1767. Muerto el nuncio Alberico Lucini en 1768, el rey decidía impedir la entrada de su sucesor hasta que la Santa Sede se comprometiera a satisfacer aquella pretensión ${ }^{15}$. En las mismas fechas, se im-

10 Constantino GarCÍA, El Tribunal de la Rota de la Nunciatura en España. Su origen, constitución y estructura, Roma, 1961, pp. 19-33.

11 Ibid., pp. 61-62, 68.

12 Citado en Joaquín Mantecón, La restauración... [ver n. 8], p. 17.

13 Constantino García, El Tribunal... [ver n. 10], p. 35.

14 Andrea J. SMIDT, Bourbon Regalism and the Importation of Gallicanism: the Political Path for a State Religion in Eighteenth-Century Spain, en Anuario de Historia de la Iglesia, 19 (2010), pp. 25-53; Antonio Mestre, Nueva dinastía e Iglesia nacional, en Pablo Fernández Albaladejo (ed.), Dinastía y memoria de España en el siglo XVIII, Madrid, 2002, pp. 548-567. Cfr. Carlos RODRÍGUEZ, Secularización, regalismo y reforma eclesiástica en la España de Carlos III: un estado de la cuestión, en Espacio, tiempo, forma. Serie IV, Historia Moderna, 12 (1999), pp. 355-371, quien haciendo una comparación con otros espacios católicos (Nápoles, Austria, Baviera, Toscana) relativiza el alcance del regalismo borbónico sin negar su impulso durante el reinado de Carlos III.

15 Constantino GarCÍA, El Tribunal... [ver n. 10], pp. 48, 50-51. 
plementaban o se reforzaban varios mecanismos de control monárquico sobre la esfera eclesiástica, caso de la institución definitiva del pase regio o exequatur en 1768, por el cual los documentos pontificios serían retenidos en el Consejo de Castilla para ser examinados sin que se les pudiera dar curso antes de obtener licencia regia ${ }^{16}$. Por otra parte, el monitorio de 1768 , en el que el papa derogaba las medidas de la política regalista del duque de Parma, fue contestado con una ofensiva diplomática y militar por parte de España, Francia y Nápoles, que se completaría con la redacción, por parte de Pedro Rodríguez Campomanes, del polémico fuicio Imparcial. Y el año anterior había tenido lugar la expulsión de los miembros de la Compañía de Jesús, auténtico hito en el proceso, cuyo cuarto voto de obediencia al papa se consideraba como incompatible con la fidelidad cuasi exclusiva debida al soberano ${ }^{17}$.

El ensanche de las prerrogativas regias, que descansaba en el robustecimiento del rol de protector de la Iglesia que el rey ejercía, no se puede entender como un simple ataque monárquico. Es ésta una visión demasiado reductora. El proceso se estaba llevando a cabo con la cooperación de parte del alto clero. La búsqueda de un terreno común con éste, que sirviera a la Corona para actuar con mayor eficiencia en el ideal de reforma de la Monarquía, estaría entre las bases de la sinergia entre ambos poderes ${ }^{18}$. La hegemonía de la Corona se sustentaba, de hecho, en el apoyo de la jerarquía eclesiástica a sus iniciativas. El alto clero prestaba su capacidad discursiva para justificarlas ${ }^{19}$. También allegaba abundantes recursos materiales para el monarca ${ }^{20}$. Y, no se olvide, el espaldarazo a la extinción de la Compañía de Jesús, en 1771, provino de los propios obispos $^{21}$.

16 Christian Hermann, L'Église d'Espagne sous le Patronage Royal (1476-1834). Essai d'ecclésiologie politique, Madrid, 1988, pp. 29-30; Rafael OlaECHEA, Las relaciones... [ver n. 3], pp. 24-26.

17 Teófanes EgIDO e Isidoro PINEDO, Las causas «gravísimas» y secretas de la expulsión de los jesuitas por Carlos III, Madrid, 1994, pp. 51-52.

18 Véase Gabriel PaqueTTE, Enlightenment, Governance, and Reform in Spain and its Empire, Basingtoke / New York, 2008, pp. 56-92.

19 Antonio CALVO, «Aquel que manda las conciencias...». Iglesia y adoctrinamiento político en la Monarquía Hispánica preconstitucional (1780-1808), Cádiz, 2011; Antonio CARRERAS y Mercedes GRANJEL, Regalismo y policía sanitaria. El episcopado y la creación de cementerios en el reinado de Carlos III, Hispania Sacra, 57 (2005), pp. 589-624.

20 Rafael TORRES, El precio de la guerra. El Estado fiscal-militar de Carlos III (1779-1783), Madrid, pp. 103-126.

21 Teófanes EgIdo, Actitudes regalistas de los obispos de Carlos III, en Carmen María CREMAdes (dir.), Estado y fiscalidad en el Antiguo Régimen, Murcia, 1989, pp. 67-83 
Las eclesiologías dominantes entre los prelados de aquellos años, con sus referencias al retorno a una disciplina de la Iglesia primitiva desprovista de los abusos introducidos por la curia romana, a los derechos del monarca sobre lo eclesiástico o al aumento del poder de los obispos en detrimento de la Santa Sede, resultaron ser un punto de apoyo fundamental de la Corona ${ }^{22}$. Para la regeneración de la Monarquía era necesario, se estimaba, reducir paulatinamente el protagonismo de Roma. Esto suponía, evidentemente, cercenar en lo posible la jurisdicción del nuncio, su principal representante, aumentando en lo posible la de los agentes sobre los cuales el rey pudiera tener el mayor control posible. Y era, por cierto, buena parte del episcopado el que protestaba con fuerza contra las intromisiones del nuncio, tomando así la delantera a la Corona en sus intervenciones contra éste ${ }^{23}$.

\section{Una lealtad ambigua}

Entre los argumentos de la Corona en contra del nuncio (y, por extensión, de la Santa Sede) se encontraban los decretos del Concilio de Trento que promovían la jurisdicción ordinaria de los obispos ${ }^{24}$. Se podría pensar que el hecho de que el rey eligiera a sus propios candidatos al episcopado garantizaba su control indirecto sobre el espacio jurisdiccional que correspondía a los obispos. Reforzando la posición de los prelados, la Corona reforzaría la suya propia.

Pero la confirmación de los obispos, que correspondía solamente al papa (y que, por las escasas ocasiones en que se negó a los candidatos propuestos parecía una mera cuestión de trámite), implicaba que los únicos agentes a los cuales el rey no podía destituir sin expreso consentimiento de otra entidad soberana se encontraban en el alto clero. Esto, que suponía la existencia de una doble fuente de legitimidad de la jerarquía eclesiástica (y, en consecuencia, de su lealtad com-

22 Los trabajos más sólidos (a los que cabe objetar principalmente su concepción demasiado rígida del jansenismo, en contraste con la definición más flexible que nosotros usamos) para conocer estas corrientes siguen siendo los de Emile APPOLIS, «Le tiers parti» catholique au XVIII siècle, entre Fansénistes et Zelanti, Paris, 1960; ID., Les jansénistes espagnols, Bordeaux, 1966; Joël SAUGNIEUX, Les jansénistes et le renouveau de la prédication dans l'Espagne de la seconde moitié du XVIII siècle, Lyon, 1976; ID., Le jansénisme espagnol du XVIIIe siècle, ses composantes et ses sources, Oviedo, 1975. Véase también el excelente estudio de Francesc TORT, El obispo de Barcelona Fosep Climent i Avinent. 1706-1781. Contribución a la Historia de la Teología pastoral tarraconense en el siglo XVIII, Barcelona, 1978.

23 Constantino García, El Tribunal... [ver n. 10], pp. 39-40, 46.

24 Novísima recopilación... [ver n. 9], libro II, título IV, leyes V, VI, VII. 
partida o su potencial deslealtad) generaba una desconfianza permanente que se fue agudizando a finales de siglo.

Si se evoca esta cuestión es porque, en lo que hace a su procedimiento selectivo, el personal de la Rota de la nunciatura se encontraba en una situación similar a la de los obispos. De ahí el énfasis puesto durante las negociaciones previas a la creación del tribunal sobre quién debería nombrar, y bajo qué condiciones, a los que serían empleados en el mismo. En las minutas que precedieron a la redacción definitiva del breve Administrandae iustitiae zelus se proyectaba que el tribunal estuviera formado por seis jueces auditores, un fiscal y un asesor, todos ellos españoles. Se consiguió que los seis auditores, aunque nombrados por el papa, fuesen propuestos por el rey, como se hacía con los obispos. Pretendía el rey, también, que los nombramientos del fiscal y del asesor se hicieran mediante el mismo procedimiento. Pero Roma no cedió en este punto, reservándose el nombramiento de ambos empleos sin previa propuesta del rey, y comprometiéndose únicamente a que sus electos fueran del agrado de éste ${ }^{25}$.

El rey parecía garantizar su influjo sobre el tribunal de la Rota mediante la elección de los auditores. No obstante, las precauciones tomadas para que los empleados explicitaran su fidelidad a la Corona son elocuentes de esa desconfianza permanente (o, si se prefiere, preventiva o anticipatoria) con respecto al alto clero.

La cuestión del juramento realizado para tomar posesión de las plazas ofrece una interesante perspectiva al respecto. Los empleados de la Rota debían pronunciar ante el nuncio apostólico un juramento de fidelidad a la Santa Sede antes de comenzar a ejercer sus funciones. En él no se citaba a la persona del rey ni a la Monarquía. Pero en la primera vacante de auditor, de 1779, la Corona se adelantó a este juramento de fidelidad estableciendo otro por el cual el electo se comprometía a ejercer sus funciones «sin perjuicio de la fidelidad debida Su Majestad, y en cuanto no se perjudiquen las regalías de la corona, Leyes del Reino, disciplina de él, legitimas costumbres, concordatos, y otros cualesquiera derechos adquiridos». Era un juramento de fidelidad previo al realizado ante el nuncio y que, en cierta medida, lo neutralizaba. Llegado el breve de nombramiento del nuevo auditor desde Roma, la Cámara de Castilla dio el pase al documento indicando en el dorso que el electo debería hacer este

25 Constantino GARCÍA, El Tribunal... [ver n. 10], pp. 52-53. Para mayores detalles sobre la estructura del tribunal, que comprendía dos secretarias de justicia y varios oficiales cuyo nombramiento correspondía al nuncio, pp. 71-83. 
juramento ante el decano del tribunal, quien actuaría como representante del rey. Y lo mismo valdría para todos los futuros nombramientos de los empleados de la Rota ${ }^{26}$.

El hecho provocó la enérgica protesta del nuncio. Desde palacio, el conde de Floridablanca respondió que el juramento se hacía únicamente por lo respectivo a los honores de consejeros reales de que todos ministros de la Rota disfrutaban. Pero sin duda la maniobra tenía otras implicaciones. En septiembre de 1776 se había dispuesto que los auditores, el fiscal y el asesor (los dos últimos de nombramiento directo por la Santa Sede) se pudieran titular «consejeros del rey», con el tratamiento, honores y exenciones de los eclesiásticos empleados en los consejos de la Monarquía ${ }^{27}$. La medida estaba lejos de ser inocente ${ }^{28}$. La concesión de los honores de consejeros del rey se dirigía a fijar un punto de anclaje de los auditores con el monarca. En uno de los documentos del expediente se revelaba esta intención cuando se escribía que los ministros de la Rota no solamente deberían poder usar los honores de consejero real sino que, «porque se juzgasen más dependientes del rey», habría que darles un título formal de consejero honorífico que justificara el juramento de fidelidad a la Corona ${ }^{29}$.

\section{EL ENFRENTAMIENTO DE $1799^{30}$}

En este contexto de lealtades compartidas, alterado ya por la convergencia de la situación política creada por la Revolución francesa con un movimiento de escalada regalista que estaba alcanzando su punto culminante, llegaba el decreto

26 MADRID-ARCHIVO HISTÓRICO NACIONAL [=AHN], Estado, leg. 3438, exp. 2.

27 Ibidem.

28 El mismo año, de hecho, se había intentado que el tribunal pasara a llamarse «Real Consejo de la Rota», lo cual fue rechazado de plano por el nuncio para evitar su equiparación a los tribunales de la Monarquía. Constantino GARCÍA, El Tribunal... [ver n. 10], p. 82.

29 AHN Estado, leg. 3438, exp. 2.

30 Para lo que sigue, utilizo un voluminoso manuscrito sin foliar que, habiendo pertenecido a Julio Urquijo (1871-1950), se conserva en la Biblioteca del Parlamento Vasco. Se compone de la copia de varios documentos referentes al real decreto de 5 de septiembre de 1799 , la mayoría de los cuales se han podido cotejar con los transcritos por Luis Sierra [ver n. 3], que éste consultó en el Archivo del Congreso de los Diputados, y con los custodiados en ROMA-ARCHIVIO SEGRETO VATICANO [=ASV], Nunziatura Madrid, busta 198. Lleva por título Expediente que ha motivado el Real Decreto de 5 de septiembre de 1799 sobre las facultades que nuestro católico Monarca Carlos IV declaró tener los Obispos en la Sede Vacante de Nuestro Santo Padre Pío VI [en adelante, citado como Expediente]. Disponible en http://www.liburuklik.euskadi.net/handle/10771/8601 [Consultado 23-3-2017]. 
de 5 de septiembre de $1799^{31}$. El nuncio esperó acontecimientos hasta enviar al monarca, el día 24 del mismo mes, una representación en la que cuestionaba incluso la fidelidad del rey a los pactos que le unían con Roma y, en consecuencia, le advertía de estar en peligro de apartarse «del afecto, filial amor y piadosa constante adhesión de Vuestra Majestad a la Santa Sede Apostólica y vicario de Cristo en la tierra». En otras palabras, le acusaba de deslealtad.

El asunto que más parecía interesar al nuncio era el del tribunal de la Rota. Precisamente, porque cuestionaba el origen de su propia jurisdicción. ¿Es que el nuncio tenía jurisdicción propia? La escasa precisión del breve de creación del tribunal en torno a las comisiones de causas a los auditores conllevaba la ambigüedad interpretativa. ¿Es que su comisión a los auditores de la Rota era un acto de jurisdicción, o un mero acto procedimental previsto en el breve? En definitiva, ¿era la Rota un tribunal ordinario, y podía por lo tanto funcionar al margen del nuncio? La respuesta podía cambiarlo todo porque la cuestión remitía a un debate de mucha mayor resonancia.

En su representación al rey, el nuncio Felipe Casoni argumentaba que la Rota ni tenía, ni ejercía jurisdicción ordinaria, sino subdelegada del nuncio quien, a su vez, la recibía del papa. En consecuencia, los jueces del tribunal no tenían sino la jurisdicción subdelegada por el nuncio en cada acto de comisión de la causa $^{32}$. Por lo tanto, el real decreto venía a «trastornar no solo su jurisdicción apostólica, sino el bien meditado gobierno, curso y sistema de la Rota española, y la más constante y legítima práctica de la Nunciatura». El nuncio, para terminar su escrito, no dudaba en amenazar con la suspensión de todos los asuntos de la nunciatura propiciando, en consecuencia, «graves inconvenientes, males y perjuicios», a no ser que el monarca diera un paso atrás y detuviera cualquier innovación en la materia ${ }^{33}$.

Mariano Luis de Urquijo, secretario del despacho de Estado en interinidad desde el año anterior, respondió el 12 de octubre. El documento es un riquísimo compendio de los argumentos manejados por el regalismo cenital de finales del siglo XVIII. Constituye un ejemplo acabado del antirromanismo en sus múltiples expresiones eclesiológicas. El ministro advertía de que el rey

31 Para la política regalista de estos años, Carlos RoDRíguEZ, Don Luis de Borbón, el cardenal de los liberales (1777-1823), Toledo, 2002, 403 p. Véase también, sobre el primer proyecto desamortizador, comenzado en 1798, Marta FRIERA, La desamortización de la propiedad de la tierra en el tránsito del Antiguo Régimen al Liberalismo (La desamortización de Carlos IV), Gijón, 2007.

32 Expediente [ver n. 30].

33 Ibidem. 
no sólo podría limitar, si así consideraba que debía hacerlo, las facultades del nuncio, sino que

en virtud del poder supremo de su Soberanía, de donde dimana toda jurisdicción temporal, [podría] mandar que los Tribunales Eclesiásticos juzgasen las causas con la misma real jurisdicción que juzgan los demás Tribunales del Reino, y en esto no haría más que volver a tomar sus propios derechos, que si bien han sido temporal y graciosamente concedidos, no han podido, ni debido ser jamás enajenados ${ }^{34}$.

En el discurso de Urquijo, las consideraciones eclesiológicas o canónicas se reducían ostensiblemente en favor del argumento superior del origen divino de la soberanía regia. El papa no era según él, como sostenían las tesis ultramontanas, «obispo de todo el mundo y monarca a quien Dios ha dado una potestad ilimitada». El poder temporal no quedaba subordinado al poder espiritual, ni el pontífice romano era el único monarca de derecho divino, ya que era innegable que también «los Reyes reciben de Dios su soberanía». Podían éstos romper con los pactos establecidos, en especial referencia a la jurisdicción del nuncio en el tribunal de la Rota, porque no podían vincularse a un pacto sobre unos derechos que eran de institución divina, y que además la Santa Sede no poseía, sino que había usurpado al episcopado ${ }^{35}$.

En el tribunal de la Rota las disensiones se hicieron patentes desde octubre. La tendencia prorromana, representada por una minoría de auditores, se oponía a la observación del decreto defendiendo la posición del nuncio frente a una mayoría regalista que abogaba por su pronta aplicación, situándose así de parte del secretario del despacho de Estado.

Dos auditores manifestaron su disconformidad con el decreto en memorial elevado al monarca el 24 de octubre. En su escrito, consideraban preciso informar al rey de las «funestas consecuencias (...), perjuicios incalculables, ya espirituales ya temporales» que podrían derivarse de la ejecución de aquellas medidas. Saliendo de la «inacción de perros mudos» en que tenía al alto clero su excesiva dependencia de la Corona, aseguraban «acreditar simultáneamente la fidelidad y lealtad», en equilibrio cada vez más complicado en aquellas circunstancias, «de rendidos vasallos de Vuestra Majestad y la calidad de reverentes súbditos del Vicario de Cristo». Recordaban a Carlos IV que la potestad regia, «contenta con lo

\footnotetext{
34 Ibidem.

35 Ibidem.
} 
de César», debería dejar «en libertad al sucesor de San Pedro para que mantenga la mano al timón en el gobierno de la Iglesia» ${ }^{36}$.

En el escrito resuena el eco de una línea eclesiológica que insistía en la idea del equilibrio entre ambas potestades mediante el respeto recíproco de sus respectivos límites. En lo que hacía a la potestad eclesiástica, el monarca debería aceptar el siguiente principio con todas sus consecuencias: Jesucristo habría transferido la potestad de jurisdicción sobre la Iglesia a San Pedro; solamente a él y no a cada uno de los apóstoles, con lo que le concedió «la Superintendencia sobre los prelados y sobre el común de los fieles» ${ }^{37}$. Ante el argumento (episcopalista, aunque utilizado en aquel contexto con intenciones regalistas) de que todos los apóstoles habían recibido de Jesucristo la potestad y autoridad apostólica, ambos auditores concluían que era el sucesor de San Pedro quien, «como único Vicario de Cristo en la tierra, es el que la tiene omnímoda, universal y radicada, única y privativamente en su persona, de la cual, como de un Centro común, salen las líneas a la circunferencia de cuantos la ejercen ${ }^{38}$. Era el mismo concepto que de la jerarquía tenía el nuncio: el papa se situaba en una posición de preeminencia y superioridad jerárquica respecto de los demás obispos. No era un primus inter pares de cuyas facultades pudiera disponer el resto del episcopado.

Los auditores defendían, así, la autoridad jurisdiccional, gubernativa y legislativa del pontífice romano sobre el conjunto de la sociedad eclesiástica. Designaban como herejes o cismáticos los intentos de alterar este principio ${ }^{39}$. Y por ello, se les levantaba «una barrera insuperable a la pronta y rendida obediencia (...) a los Reales decretos de Vuestra Majestad» ${ }^{40}$. Su opción difícilmente podía ser más clara.

El grupo regalista, reforzado con el nombramiento de un auditor supernumerario, contraatacó el 25 de noviembre. En su representación al rey, daba en primer lugar cuenta de la división surgida en el tribunal. Los auditores se pronunciaban claramente a favor de la pronta ejecución del decreto y realizaban una decidida defensa de la jurisdicción ordinaria del tribunal negando, por consiguiente, la jurisdicción del nuncio ${ }^{41}$. Esto implicaba que la Rota podría, dadas

\footnotetext{
36 Ibidem.

37 Ibidem.

38 Ibidem.

39 Ibidem.

40 Ibidem.

41 Luis SIERRA, La reacción... [ver n. 3], 250-251.
} 
las circunstancias, funcionar como cualquier otro tribunal regio. En este sentido, su postura era nítida.

El rey se mostraría agradecido a este grupo, asegurando estar muy satisfecho con su representación, al tiempo que expresaba su desagrado ante la escrita por los dos auditores que se habían pronunciado en favor de los derechos de la Santa Sede ${ }^{42}$.

\section{EL PERSONAL DE LA ROTA}

Comprender la acritud del enfrentamiento y la profundidad de la escisión de los auditores requiere de un conocimiento detallado de las vías de acceso al tribunal. La Rota era, además de un tribunal de apelación, un espacio de poder. Contextualizar el desacuerdo descrito, otorgando un sentido a la defensa de cada posición por los actores que en él participaron, pasa por saber quiénes eran éstos y cómo habían accedido a sus puestos.

Con este objetivo, hemos revisado todos los expedientes que hemos podido localizar (tanto los de los eclesiásticos que fueron electos auditores, como de los pretendientes que no fueron seleccionados para las plazas) durante la última década del siglo XVIII ${ }^{43}$. Los expedientes incluyen relaciones de méritos, memoriales solicitando el puesto y, en el caso de aquellos que fueron electos, documentación relacionada con el proceso de nombramiento (trámites administrativos, recomendaciones). Estas fuentes permiten reconstruir detalladamente las carreras, identificar a los agentes que intervenían en la selección y sopesar los factores que incidían en la elección o rechazo de un candidato.

\section{La Rota, espacio de poder}

Producida la vacante de una plaza, el nuncio la comunicaba a la Secretaría del despacho de Estado para que activara los trámites conducentes a la selección del candidato que habría de ocuparla. Los pretendientes que aspiraran a obtenerla enviaban a la secretaría su memorial con una relación de méritos. Esta documentación se remitía a la Cámara de Castilla, donde se hacía una lista de

42 Expediente [ver n. 30].

43 Esta documentación se encuentra en diversos legajos del AHN Estado, 3412-3451. 
pretendientes antes de elevar la consulta al monarca. Formada la consulta, se enviaba una terna de candidatos al rey, quien elegía al que después sería propuesto para la confirmación pontificia ${ }^{44}$. Comunicada la decisión al electo, éste presentaba en la Secretaría del despacho de Estado su aceptación para que se cursara el nombramiento en Roma. Finalmente, recibido el breve con el nombramiento, el Consejo de Castilla daba el pase al documento y lo entregaba al electo, a quien después daría posesión el nuncio.

Como va dicho, solamente los seis auditores eran presentados por el rey. El fiscal y el asesor eran nombrados directamente por la Santa Sede previa negociación con el monarca. En total, hubo ocho vacantes de auditor desde el establecimiento definitivo del tribunal en 1774 hasta 1800. En esta fecha hubo un aumento de dos auditores supernumerarios. Contamos por lo tanto, para nuestro análisis, con 16 auditores más los 49 pretendientes que aspiraron a una plaza en las tres vacantes habidas en la última década del siglo.

Lo que resulta del examen de las fuentes es que en la Rota se encontraban personas estrechamente relacionadas con la alta jerarquía eclesiástica. La mayoría de los que formaron parte de ella eran, de hecho, potenciales obispos. Con perfil de abogados, en un periodo en el que los especialistas en teología iban perdiendo terreno en la selección del episcopado, habían ocupado anteriormente aquellos puestos que conducían a ser considerado por la Cámara de Castilla para algún obispado. Nueve de los auditores habían sido, en efecto, vicarios generales o canónigos de oficio de catedrales, dos de los pasos clave para acceder al episcopado $^{45}$. Los siete restantes habían ejercido, en casi todos los casos, puestos de responsabilidad en la administración de algún obispado. Entre los 49 pretendientes, casi la mitad fueron vicarios generales, y 14 habían obtenido alguna canonjía de oficio.

De los 16 auditores dos fueron elevados al episcopado ${ }^{46}$. Y otros 6 fueron propuestos por la Cámara para alguna mitra. Si se añade a éstos el resto del personal de la Rota (fiscal, asesor), tenemos que al menos nueve eclesiásticos empleados

44 El rey podía, sin embargo, prescindir totalmente de la Cámara de Castilla y elegir al auditor por real decreto. De hecho, mandó corregir un borrador del breve de creación del tribunal de la Rota en el que se expresaba que elegiría sus candidatos entre los propuestos por la Cámara de Castilla, lo que fue considerado una condición previa inaceptable. Constantino GARCÍA, El Tribunal... [ver n. 10], p. 52.

45 Andoni ARTOla, De Madrid a Roma. La fidelidad del episcopado en España (1766-1833), Gijón, pp. 62-67.

46 Lorenzo Gómez Haedo, auditor de la Rota en 1774, obispo de Segorbe de 1783 a 1808; Manuel Verdugo Albiturría, auditor en 1793, obispo de Canarias en 1796. 
en ella figuraron como candidatos a obispos ${ }^{47}$. El paso por el tribunal se fue configurando como una etapa hacia la más alta jerarquía, como lo muestra el hecho de que los cuatro últimos auditores nombrados llegaran a entrar en la categoría de candidatos a la mitra.

El carácter del tribunal como espacio de competencia altoclerical puede observarse en las ternas que la Cámara fue elevando al rey en cada vacante. En la primera, figuraban cinco candidatos de los cuales uno acabaría siendo obispo, otro que sería propuesto en varias ocasiones para una mitra, otro que había sido vicario general del arzobispado de Sevilla, y uno que había sido canónigo de ofi$\mathrm{cio}^{48}$. De los cuatro propuestos para la vacante de 1784, dos lo serían también para el episcopado en otras fechas ${ }^{49}$. El auditor nombrado en 1792 sería hecho cuatro años después obispo de Canarias ${ }^{50}$. En la consulta para la provisión de la vacante de 1794 había seis candidatos, de los cuales uno acabó siendo obispo de Valladolid y otro fue propuesto para la mitra en dos ocasiones ${ }^{51}$.

47 Juan Manuel Toubes, auditor en 1774, propuesto la Cámara en 1777 para el obispado de Mallorca, para el de Lugo en 1786, apareció en una lista de candidatos para el obispado de Ceuta en 1779 (VALLADOLID-ARCHIVO GENERAL DE SIMANCAS [=AGS], Gracia y 7usticia [=Gf], legs. 318, 320, 323); Antonio López Sánchez, asesor del nuncio en la Rota desde 1774, propuesto para la sede de Ciudad Rodrigo en 1782 (AGS Gf, leg. 323). Juan Antonio Quilez, auditor desde 1779, propuesto en 1783 para el obispado de Cartagena (AGS G7, leg. 326). Joaquín Palacín, auditor desde 1785, propuesto para los obispados de Valladolid y Ávila en 1801 (AHN Consejos, legs. 15479, 19510). José María Villodas, fiscal desde 1793, consultado para Ávila en 1799 (AHN Consejos, legs. 15479); Miguel Ochoa, propuesto para Guadix, Canarias y Tudela entre 1796-1798 (AHN Consejos, legs. 15454, exp. 2; 15461, exp. 2; 16906); José Espiga, auditor desde 1799, propuesto para Palencia (AHN Consejos, leg. 15475). Matías Robles, auditor supernumerario en 1800, había sido propuesto en numerosas ocasiones para obispados, y electo para la mitra de Jaén en 1793, que rechazó (AHN Consejos, leg. 15451). Habría que añadir a la lista a Juan José Aldama, de quien, aunque no se ha encontrado ninguna propuesta, se afirmaba en una nota que «ha sido propuesto para obispados» (AHN Estado, leg. 3440, exp. 7).

48 AHN Estado, leg. 3438, exp. 2. Se trata de Antonio Martínez de la Plaza, propuesto en segundo lugar para la plaza de auditor, obispo de Canarias (1785-1790) y Cádiz (1790-1800); José Marcos Verdugo, propuesto en varias ocasiones para mitras (AGS Gf, legs. 308, 311, 310, 320, 321, 317, $351,510)$.

49 AHN Estado, leg. 3450, exp. 4. Francisco Arascot, propuesto para Barbastro, Astorga y Burgos en 1790-1791 (AHN Consejos, legs. 19064, 15436, 15439); Joaquín Palacín. Véase supra, nota 47.

50 Manuel Verdugo Albiturría. Véase supra, 46.

51 AHN Estado, leg. 3448. Vicente Soto, propuesto en tercer lugar para auditor, obispo de Valladolid (1803-1818). Antonio de la Cuesta, propuesto para los obispados de Gerona y Málaga en 1798-1799 (AHN Consejos, leg. 15471; José Manuel CuENCA, Sociología de una élite de poder en España e Hispanoamérica contemporáneas: la jerarquía eclesiástica (1789-1965), Córdoba, 1976, p. 101). 
En lo que hace a los pretendientes, cuatro de las personas que aspiraron a la plaza en las vacantes habidas entre 1792 y 1798 acabaron siendo obispos ${ }^{52}$. Y otras seis entraron en alguna ocasión en alguna terna de la Cámara para serlo ${ }^{53}$.

Es importante señalar que la selección de los empleados en el tribunal (y del alto clero, en general) se realizaba en el marco de una circulación de recursos que transcendía su carrera individual. Este es un punto fundamental a la hora de comprender su posicionamiento eclesiológico. Su fidelización pasaba por incluirles en un espacio de interacciones e intercambios que superara lo eclesiástico y que, como se decía en el documento citado más arriba, les hiciera «más dependientes del rey».

La fidelización del alto clero se hacía, en buena parte, por la inclusión de sus parientes, amigos o compañeros en un ámbito común que les uniera a la figura regia. Por ejemplo, Juan Antonio Trespalacios hacía referencia, al solicitar una plaza en 1796, a los méritos propios, pero también a los de sus hermanos y demás parientes -particularmente a los de su difunto tío, consejero del Consejo de Indias, cuyos servicios incluía en su propia relación de méritos- ${ }^{54}$. Pablo Acedo Rico evocaba los méritos de su difunto padre, gobernador del Consejo de Castilla, al solicitar una vacante de auditor ${ }^{55}$. Y Álvaro Valcárcel consideraba, por su parte, que el mérito de su difunto hermano, el marqués de Medina, en la batalla de Cabo Verde, en 1780, debería ser recompensado con una plaza en la Rota ${ }^{56}$.

Son solamente algunos ejemplos, que se podrían multiplicar, de cómo los integrantes de unos mismos grupos, fuertemente conectados, se situaban en distintas esferas funcionales de la Monarquía teniendo como punto de referencia común a la persona regia, distribuidora de las gracias que apuntalaban o confir-

52 Pedro Antonio Trevilla, pretendiente en 1792 (AHN Estado, leg. 3440), obispo de Córdoba (18051832); José Vicente Lamadrid, pretendiente en 1792 (AHN Estado, leg. 3412), obispo de Málaga (1800-1809); Jerónimo Castillón Salas, pretendiente en 1792 (AHN Estado, leg. 3423), obispo de Tarazona (1815-1835); Ildefonso Cañedo, pretendiente en 1798 (AHN Estado, leg. 3417), obispo de Málaga (1814), arzobispo de Burgos (1825-1829).

53 Gabriel Hevía, propuesto en 1796 para los obispados de Tudela y Canarias (AHN Consejos, legs. 15454, 15462); Manuel Francisco López Montenegro, propuesto en 1796 para Tudela (AHN Consejos, leg. 15462); José Fernández Velasco, propuesto para varias mitras entre 1785-1789 (AGS Gf, leg. 326-327); Agustín Galindo, propuesto para los obispados de Málaga y Teruel (AHN Consejos, legs. 19510, 15471); Francisco Antonio Asas, propuesto para el obispado de Lugo (AHN Consejos, leg. 16909); Francisco Valdivia Donoso, propuesto en 1794 para el obispado de Barcelona (AHN Consejos, leg. 18872).

54 AHN Estado, leg. 3440, exp. 11.

55 AHN Estado, leg. 3430, exp. 2.

56 AHN Estado, leg. 3428, exp. 2. 
maban los procesos de movilidad ascendente que estaban experimentando. La concesión de honores es un buen indicador de esto. No es casual que siete cruces de la Orden de Carlos III, creada para premiar la fidelidad y los servicios a la Corona, se otorgaran a eclesiásticos empleados en la Rota ni que, entre los pretendientes a plazas del tribunal, fueran seis los que las obtuvieran ${ }^{57}$.

Es evidente, teniendo en cuenta lo dicho, que las carreras de este alto clero no se reducían a un mero cumplimiento de cometidos prácticos en la sociedad eclesiástica. Respondían también a una lógica de servicio a la Monarquía que se realizaba en el seno de grupos de personas conectadas entre sí que trascendía el espacio eclesiástico.

\section{La superposición de lo eclesiológico y lo político a finales del siglo XVIII}

La documentación consultada muestra un fenómeno que la historiografía cada vez conoce mejor: la agudización de la competencia por el acceso al monarca a finales del siglo XVIII, acceso que se iba concentrando en un reducido número de personas al tiempo que se marginaban los procedimientos consensuales de reparto de recursos por parte del rey ${ }^{58}$. El apartamiento de la Cámara de Castilla, que formaba parte de este proceso, fue simultáneo al aumento de arbitrariedad decisoria y a la concentración de las vías de acceso a la persona del rey en un restringido grupo que, durante buena parte del periodo, tuvo como cabeza visible a Manuel Godoy.

El poder de actuación alcanzado por Manuel Godoy tan sólo se explica teniendo en cuenta la concentración previa de poder en el monarca, que fue

57 Domingo Codina, fiscal de la Rota de la nunciatura, caballero de la Orden de Carlos III en 1793; Juan Manuel Toubes, auditor, caballero en 1784; José Muñiz Madrigal, fiscal, caballero en 1788; Juan Antonio Quilez, auditor, caballero antes de 1792; Miguel Ochoa, auditor, caballero en 1792; Juan José Aldama, auditor, caballero en 1799; José Espiga, auditor, caballero en 1799.

Entre los pretendientes, Manuel Francisco López Montenegro, caballero en 1800; Juan Francisco Alvear, en 1794; Antonio de la Cuesta, en 1807; Gaspar Haedo Espina, en 1787; Juan Antonio Trespalacios, en 1793; Juan Antonio Llorente, en 1807.

Vicente CADENAS, Extracto de los expedientes de la orden de Carlos III, 1771-1847, Madrid, Hidalguía, 1979-1988 [en adelante, citado EEOC3], extractos 56, 68, 564, 637B, 770, 1194, 1457, 1510, 1753, 1832, 2477, 2480; AHN, Estado, Carlos III, exp. 777, f. 8r ${ }^{\circ}$.

58 Sobre esto, Antonio CALVO, Cuando manden los que obedecen. La clase política e intelectual de la Espana preliberal (1780-1808), Madrid, 2013, pp. 159-188. Antonio CALVO, Manuel Amador GONZÁLEZ, Patronazgo y clientelismo en la corte de Carlos IV: particularidades y continuismos, en José María ImÍZCOZ, Andoni ARTOLA (coords.), Patronazgo y clientelismo en la Monarquía Hispánica, Bilbao, 2016, pp. 385-408. Francisco ANDÚJAR, Nepotismo, Clientelismo y Fidelidad. De Floridablanca a Godoy (1789-1798), en Cuadernos de Historia Moderna. Anejos, VII (2008), pp. 179-211. 
informalmente delegada en el favorito ${ }^{59}$. Su papel como mediador, y el del monarca como fuente única de mercedes al margen de las instancias consultivas que habían presidido su distribución, se puede ilustrar con numerosos ejemplos. Citemos el caso de Antonio de la Cuesta, quien contaba con Godoy para obtenerle una plaza de auditor de la Rota que (como se verá más adelante) nunca obtuvo ${ }^{60}$. Gaspar Melchor de Jovellanos, durante su breve etapa como secretario del despacho de Gracia y Justicia, medió ante el propio Godoy para intentar conseguir la concesión de una de las plazas a su sobrino, el futuro arzobispo de Burgos Ildefonso Cañedo ${ }^{61}$. Por su parte, el auditor Evaristo Bejarano le escribió señalando que, como «criatura» suya, aspiraba a obtener con su apoyo una canonjía o una dignidad de catedral con la cual dignificar su empleo en el tribunal de la Rota ${ }^{62}$. Y, por poner un último ejemplo, cuando Juan Lucas López quiso acceder a una plaza, contactó con el secretario del despacho de la Guerra para que éste, a su vez, mediara ante Godoy recomendando su pretensión ${ }^{63}$.

Esta concentración de poder en el monarca, parapetada tras el favorito, se fue correspondiendo progresivamente con la radicalización de posturas en el seno de la sociedad eclesiástica. Son procesos concomitantes e interrelacionados. De hecho, las facciones enfrentadas por obtener el favor regio recubrían frecuentemente sus aspiraciones con un revestimiento eclesiológico ${ }^{64}$. La promoción personal o grupal y la toma de posición en torno a la estructuración interna de la sociedad eclesiástica o a la influencia de la Santa Sede en España eran elementos que se fueron imbricando progresivamente. No en vano, algunos contemporáneos estimaron que los argumentos ideológicos eran ante todo un recubrimiento justificativo de los conflictos asociados a la obtención de puestos de influencia. En este sentido escribía el embajador francés a su ministro de Asuntos Exteriores en enero de 1801, afirmando que, en España, el jansenismo era el pretexto utilizado para influir en el ánimo del rey e intentar conseguir la destitución de los enemigos políticos ${ }^{65}$.

\footnotetext{
59 Emilio LA PARRA, Manuel Godoy. La aventura del poder, Barcelona, 2002, pp. 242-253.

60 AHN Estado, leg. 3448, exp. 3.

61 AHN Estado, leg. 3417, exp. 5.

62 AHN Estado, leg. 3428, exp. 4.

63 AHN Estado, leg. 3429, exp.13.

64 Emilio La PARRa, Iglesia y grupos políticos en el reinado de Carlos IV, en Hispania Nova, 2 (20012002). Disponible en: http://hispanianova.rediris.es [Consultado 10-07-2015].

65 Citado en Vittorio SCIUTI, Inquisizione spagnola e riformismo borbonico fra sette e ottocento. Il dibattito europeo sulla soppressione del «terrible monstre», Firenze, 2009, p. 253.
} 
En síntesis, la arbitrariedad en las decisiones y la inestabilidad política repercutían en el plano eclesiológico y éste, a su vez, en la estructuración de los grupos en lucha por el acceso al rey. Veamos un ejemplo.

En 1793 Antonio de la Cuesta fue recomendado a Manuel Godoy por el entonces Inquisidor General, fray Manuel Abad Lasierra, para la plaza de asesor del tribunal. Los dos compartían ideario. Antonio de la Cuesta, eclesiástico con una carrera perfectamente apta para el episcopado, había sido uno de los fundadores de la Real Sociedad Económica de Ávila, ciudad en cuya catedral había ocupado varios puestos administrativos y de la que era arcediano titular desde 1790. Ya durante su época de estudiante en la Universidad de Valladolid se había formado en una eclesiología antirromana que subrayaba en su relación de méritos ${ }^{66}$. Formó parte, después, del círculo reunido en torno a la condesa de Montijo, del cual también participaban Félix Amat, Joaquín Lorenzo Villanueva, Estanislao Lugo, Juan Meléndez Valdés o Gaspar Melchor de Jovellanos, entre otros ${ }^{67}$. En este último ámbito no sólo se alimentaba su pensamiento eclesiológico o se modulaban sus ideas, sino que, al mismo tiempo, desde él se le protegía probablemente ante el rey para que fuera avanzando en su carrera ${ }^{68}$.

Manuel Abad Lasierra, por su parte, había cooperado con Pedro Rodríguez Campomanes, desde 1771, examinando los archivos de monasterios benedictinos de Cataluña y Aragón en materias relacionadas con el patronato regio. Era miembro de la Real Academia de la Historia desde 1773, socio de la Real Sociedad Económica de Jaca y sus Montañas desde 1783, y autor de varios manuscritos en defensa de los derechos de la Corona sobre las estructuras eclesiásticas ${ }^{69}$. Obispo de Ibiza, sede de nueva creación para la que el rey requería de una persona de la máxima confianza, pasó en 1787 a la sede de Astorga con recomendación del conde de Floridablanca. Coincidiendo con el regreso desde Francia del conde de Aranda, fue hecho Inquisidor General en $1793^{70}$. Su actuación en favor de Antonio de la Cuesta se enmarcaba en una trayectoria previa en la que habían interactuado con unas mismas personas, en unas referencias similares sobre la

66 AHN Estado, leg. 3426, exp. 9.

67 Paula Demerson, María Francisca de Sales Portocarrero, condesa de Montijo. Una figura de la Ilustración, Madrid, 1975, p. 311.

68 Andrés SÁnCHEZ, Jorge DeMERSon, Los hermanos D. Antonio y D. Ferónimo de la Cuesta y Torre, canónigos de la Santa Apostólica Iglesia de Ávila (1755-1828), en Cuadernos Abulenses, 19 (1993), p. 112.

69 El mismo era consciente de las críticas que podía recibir en tanto que «regalista». Gabriel PAQUETTE, Enlightenment... [ver n. 18], p. 56.

70 Jorge DEMERSON, Ibiza y su primer obispo: don Manuel Abad y Lasierra, Madrid, 1980. 
estructuración de lo eclesiástico y en la frecuentación de unos mismos espacios de sociabilidad.

La plaza que se pretendía era una de las que la Santa Sede proveía sin intervención del monarca. El papa, accediendo parcialmente a la petición, propuso darla al auditor Froilán Calixto Cabañas, para que la resulta del ascenso de éste se otorgara por el rey a Antonio de la Cuesta. Sin embargo, mientras el asunto se tramitaba en Roma, se hizo llegar una delación a Manuel Godoy en la que se acusaba a Antonio de la Cuesta de ser «hombre de perversa doctrina y [que] hablaba contra la Silla Apostólica y contra la autoridad de los Reyes», esto es, de connivencia ideológica con la Revolución francesa. En ese momento, se envió rápidamente una orden al ministerio español en Roma mandando detener el asunto de inmediato, y se avisó al Inquisidor General de que su recomendación no iba a tener efecto ${ }^{71}$. Poco después, éste caería en desgracia sin volver a disfrutar nunca de la benevolencia regia.

El ejemplo muestra el solapamiento de diversas dimensiones. Grupos (formados no solamente de eclesiásticos, sino también de burócratas, intelectuales o aristócratas) de personas fuertemente conectadas, habiendo construido una visión común de la realidad por la interacción durante sus trayectorias, se dotan de unas referencias eclesiológicas precisas -en este caso, antirromanas, regalistas, y jansenistas-. Esta identidad cohesiona al grupo, que intenta buscar el favor regio para continuar o confirmar sus procesos de promoción social en un contexto de alta competencia por los recursos distribuidos por el rey. La aparición del factor ideológico, en este caso en torno a los acontecimientos de Francia, refuerza esa cohesión, agudizando el enfrentamiento, del que se aprovechan otros grupos que igualmente aspiran a obtener el favor del monarca. Lo que resulta de ello es que la relación de fuerzas entre las distintas tendencias eclesiológicas estaba íntimamente relacionada con la carrera de los actores, con el momento político, con la situación internacional o con los apoyos con que se contaba para los ascensos.

\section{LAS RAZONES DE UNA LEALTAD}

Estamos ahora en condiciones de volver sobre la pregunta inicial: ¿cuáles eran los factores que animaron la toma de posturas del alto clero entre una u otra de las grandes opciones que se dibujaban en el horizonte eclesiológico durante la

71 AHN Estado, leg. 3426, exp. 4. 
crítica coyuntura de 1799? Como se ha expuesto antes, en el tribunal de la Rota (que puede ser visto como una expresión micro de la generalidad del alto clero) los defensores de cada una de las opciones habían llegado al culmen de un conflicto que sin duda contaba con precedentes. El análisis detallado de sus trayectorias y modos de acceso al tribunal puede ofrecer algunas respuestas a la cuestión.

Comencemos por el grupo regalista. Parecía ser José Espiga quien estaba dirigiendo la facción promonárquica en el tribunal de la Rota ${ }^{72}$. Había estudiado teología en Salamanca. Se doctoró en derecho canónico por la universidad de Valencia $^{73}$. Estableció relaciones con Mariano Luis de Urquijo durante su etapa como estudiante en Salamanca, y compartía con él la idea tardojansenista de un retorno a las prácticas de la Iglesia primitiva que, en realidad, justificaría los proyectos regalistas ${ }^{74}$. Era, según el nuncio, «amigo íntimo y condiscípulo» del ministro $^{75}$. Durante el reinado de Carlos IV fue nombrado capellán de honor de la Real Capilla $^{76}$. Estando ya en Madrid, conoció a Francisco Policarpo de Urquijo, padre del ministro, con quien mantenía «mucho trato, y comunicación» ${ }^{77}$. Por lo tanto, su proceso de ascenso era reciente y tenía que ver con las relaciones fraguadas durante su carrera, que en aquel momento, de apartamiento temporal de Manuel Godoy, conectaban con el monarca por medio de Mariano Luis de Urquijo.

Su nombramiento para la plaza de auditor, en 1798, se debía a estos vínculos. El empleo se solía proveer normalmente sobre consulta de la Cámara de Castilla. Por decreto de 17 de agosto de 1779, cada plaza estaba asignada a naturales de una demarcación territorial previamente definida, excepto una que se proveería sin atención a la naturaleza y que estaría preferentemente reservada a capellanes de honor $^{78}$. No era este el caso de la vacante para la que fue nombrado José Espiga,

72 Luis SierRA, La reacción... [ver n. 3], p. 247. Se trata de este caso, con otros fines, en Andoni ARTOLA, El acceso al episcopado en la Monarquía Hispánica (1789-1800), en Juan Bosco AMORES (dir.), Los tiempos de Espada. Vitoria y La Habana en la era de las revoluciones atlánticas, Bilbao, 2014, pp. 23-54 [pp. 49-50]

73 AGS, Gf, leg. 328.

74 Su postura, en Emilio LA PARRA, El primer liberalismo español y la Iglesia, Alicante, 1985, p. 87.

75 Citado en Luis SIERRA, La reacción... [ver n. 3], p. 247.

76 AGS, Gf, leg. 329. En una consulta de la Cámara para una ración de la catedral de Toledo, de 19 de septiembre 1788, no aparece aún como capellán de honor. De hecho, a la pieza tan solo podían pretender, según letra del decreto de 24-IX-1784, «graduados de universidad sin oficio ni beneficio». Por lo tanto, fue nombrado capellán de honor durante el reinado de Carlos IV.

77 AHN, Estado, Carlos III, exp. 1073.

78 Las plazas del tribunal deberían tener un natural de cada una de los siguientes territorios: a) Castilla la Vieja y reino de León; b) Castilla la Nueva, Madrid, Toledo, Cuenca o Guadalajara, Mancha, Extremadura, Murcia; c) Andalucía, Sevilla, Granada, Córdoba, Jaén, y Canarias; d) Aragón, Valencia, Cataluña y Mallorca; e) Galicia, Asturias, Navarra, Vizcaya, Álava; f) sin atención a la naturaleza, 
que correspondía a los naturales de Castilla la Nueva, Extremadura o Murcia, de donde no era natural ${ }^{79}$. La Cámara propuso a una serie de personas con arreglo a lo previsto, pero la candidatura fue rechazada por el rey. El 10 de octubre de 1798, Carlos IV expedía un decreto por el cual nombraba a su «capellán de honor, don José Espiga Gadea, dispensando por esta vez las calidades que requiere esta plaza ${ }^{80}$. Su acceso a la Rota se correspondía, claro está, con el proyecto monárquico de obtener un apoyo más en el tribunal de cara a hacer frente al nuncio.

Varios indicios apuntan a que el tribunal estaba siendo preparado para que mostrara una postura mayoritariamente regalista. Por decreto de 29 de julio de 1799 el rey había elevado el sueldo de los auditores. El mismo día, mandaba que desde aquel momento se pasaran al tribunal todas las cédulas y decretos del rey, «como a los demás tribunales, para su noticia y observancia». Concedía honores de consejero nato del Consejo de Castilla al decano del tribunal. Y, por último, creaba dos plazas supernumerarias de auditor ${ }^{81}$. En realidad, el rey quería que estos dos auditores supernumerarios actuaran como miembros de pleno derecho, con asistencia diaria y voto. Esto es, quería otros dos jueces regalistas que le apoyaran ante la eventualidad de tener que tomar medidas como las previstas en el decreto de 5 de septiembre ${ }^{82}$.

Los otros tres auditores regalistas (Francisco Valle Roldán, Miguel Ochoa, Evaristo Bejarano) tenían atributos similares a los de José Espiga. Todos ellos habían entrado en el tribunal recientemente, mientras Manuel Godoy o Mariano Luis de Urquijo ocupaban los más altos puestos decisorios. Francisco Valle Roldán había sido nombrado en 1794, Evaristo Bejarano en 1797, y Miguel Ochoa era

entre personas ejercitadas en la práctica forense de los tribunales de Madrid, con especial preferencia a los capellanes de honor. Novísima recopilación... [ver n. 9], libro II, título V, ley II.

79 Había nacido en Palenzuela (Burgos) en 1758. EEOC3 [ver n. 57], extracto 770.

80 AHN, Estado, leg. 3420, exp. 8.

81 Novísima recopilación... [ver n. 9], libro II, título V, ley III.

82 Es ilustrativo el caso de Miguel Ochoa, supernumerario de la Rota, y capellán de honor antes de esta fecha. En 14 de enero de 1799 Urquijo representó al nuncio que Ochoa obtuvo el nombramiento de supernumerario con opción a la primera vacante y sin necesidad de nuevo real decreto, por lo que pasaría a ocupar el puesto con voto de pleno derecho. El nuncio protestaba el 19 de enero. AHN, Estado, leg. 3446.

El puesto de auditor supernumerario que quedaría vacante como resultado de la jubilación del auditor opuesto al decreto Juan Manuel Toubes, y el paso de Miguel Ochoa a numerario, sería dado a Juan José Aldama, procedente del valle de Ayala, misma zona de la que era originaria la parentela del ministro. Como sus compañeros favorables al decreto, sus ascensos eran recientes; había sido hecho canónigo de Tuy en 1794, en 1799 obtuvo una de las cruces de la Orden de Carlos III, y en 1795 fue recomendado por Manuel Godoy al nuncio para el puesto de abreviador de la Rota, que no obtuvo. ASv, Nunziatura, Madrid, busta 196. 
auditor supernumerario desde 1798. Las fidelidades contraídas con personas que hubieran impulsado sus recientes carreras quizás puedan ofrecer alguna clave interpretativa sobre su postura ante el decreto.

En el caso de José Espiga la incidencia de este factor es evidente. Pero quizás, también, en el de Miguel Ochoa. Capellán de honor, y auditor supernumerario del tribunal, Urquijo quiso que pasara a numerario, con voto de pleno derecho, en enero de 1799, lo que provocó enérgicas protestas del nuncio ${ }^{83}$. En el momento en el que él accedía a la Rota, su hermano Francisco Javier llevaba varios años haciendo carrera en la Secretaría del despacho de Guerra ${ }^{84}$. Por su parte, Evaristo Bejarano, con dos años de antigüedad en el tribunal, había sido nombrado en las mismas fechas en que su hermano, Pedro Inocencio Bejarano, fue elevado desde la colegiata de San Isidro de Madrid al obispado de Buenos Aires ${ }^{85}$. Francisco Valle Roldán había sido nombrado auditor en 1794 con recomendación de los Cinco Gremios Mayores de Madrid, entre cuyos diputados se encontraba un tío suyo ${ }^{86}$. En síntesis, los auditores regalistas estaban viviendo procesos de movilidad ascendente (ellos y sus familias), y contaban para ello con el apoyo del entorno regio.

La radical disensión con sus opositores, no sólo sobre la forma de proceder en la vacante de la silla pontificia, sino sobre toda la fundamentación canónica y teológica que justificaba su posición y, en consecuencia, definía el papel de la Santa Sede en la estructuración de la Iglesia universal, se debe buscar en un cúmulo de factores y circunstancias previas que animaron su acción posterior. Porque no se llegaba a la defensa de tal o cual postura eclesiológica, o a la adscripción a los poco definidos partidos ultramontano o jansenista, por puro convencimiento de lo correcto de sus postulados, sino, sobre todo, por la inserción en trayectorias con otras personas con las que se iba construyendo esa misma visión de lo que deberían de ser las cosas. En este sentido, las explicaciones de la postura de los auditores se pueden buscar, en parte, en su relación con la sociedad política, su trayectoria en la jerarquía eclesiástica y en las personas que actuaron como motores de su carrera. En el caso de los auditores regalistas, el impulso de la gracia regia parecía ser, en aquel preciso contexto, su principal apoyatura.

83 Véase nota anterior.

84 Y en 1805 sería hecho consejero del Consejo de Órdenes. Ags, Dirección General del Tesoro, inv. 2, leg. 89. EEOC3, extractos 1831, 1832.

85 Para informaciones genealógicas, Caballeros de la orden de Alcántara que efectuaron sus pruebas de ingreso durante el siglo XIX, Madrid, 1956, extracto 73. EEOC3 [ver n. 57], 275. Sobre Pedro Inocencio Bejarano, Toribio Minguella, Historia de la diócesis de Sigüenza y de sus obispos, Madrid / Sigüenza, 19101913, t. III, p. 197. Los datos sobre Evaristo Bejarano, AGS, Gf, leg. 329; AHN, Estado, leg. 3428, exp. 4.

86 AHN, Estado, leg. 3448. 
En claro contraste estaba la situación de la carrera de los auditores del grupo contrario. El decano, Juan Manuel Toubes, pertenecía a la primera promoción de auditores de la Rota - por lo tanto, hacía unos 25 años que había sido nombrado- ${ }^{87}$. Juan Antonio Quilez, segundo disidente, era auditor desde $1779^{88}$. Hubo un auditor que no se pronunció junto con los anteriores, Joaquín Palacín ${ }^{89}$. Éste no aparece en ninguna de las representaciones dirigidas al rey, ni se le menciona en la documentación consultada. Pero actuó en colaboración con el nuncio apostólico redactando, al parecer, la respuesta de éste a Urquijo ${ }^{90}$. Presentaba al menos una característica común a sus dos compañeros opuestos al decreto: el nombramiento para la plaza de auditor durante el reinado de Carlos III. En septiembre de 1799 llevaba 15 años en el tribunal.

Estos tres auditores del ala prorromana no habían tenido ningún ascenso en años ni lo tendrían en el futuro. Juan Manuel Toubes había sido hecho caballero de la Orden de Carlos III en 1784, y el último nombramiento que se le conoce es el de capellán del Real Monasterio de las Franciscas Descalzas de Madrid, en 1783 ${ }^{91}$. La carrera de Juan Antonio Quilez se interrumpió con su nombramiento como juez de la Rota en $1779^{92}$. Los dos habían sido propuestos por la Cámara de Castilla para obispados, pero habían desaparecido de las consultas en $1786^{93}$. Y Joaquín Palacín tampoco había ascendido tras 1785 , año de su nombramiento como auditor.

Los vínculos de fidelidad que unían a estos tres auditores con la sociedad política se habían desvanecido, o bien no eran ya operativos para la movilidad ascen-

87 San Miguel de Osmo (1729). Bachiller en ambos derechos por la universidad de Valladolid. Doctor en Cánones por la universidad de Ávila. Catedrático sustituto de Leyes en las universidades de Salamanca y Valladolid. Visitador general del obispado de Segovia. provisor y vicario general del obispado de Orense. Fue canónigo doctoral de la catedral de Orense (1758-1774). AGS, Gf, legs. 313, 327. Filemón ARRIBAS, Relaciones y justificantes de méritos y servicios de Catedráticos, Profesores y Opositores a Cátedras, Valladolid, 1963, p. 245.

88 Abogado de los Reales Consejos (1756). Visitador general del obispado de Badajoz. Cura rector del hospital de La Latina de Madrid. Capellán de honor de la Real Capilla (1777). Auditor de la Rota española (1779). AGS, Gf, leg. 326.

89 Nacido en Barbastro en 1749. Canónigo de la catedral de Barbastro. Vicario general del obispado de Barbastro (antes de 1780). Auditor de la Rota de la nunciatura (1785). Saturnino LóPEZ NOVOA, Historia de la Muy Noble y Muy Leal Ciudad de Barbastro, y descripción Geográfico Histórica de su diócesis, Barcelona, 1861, vol. I, p. 278; vol. II, p. 115. AHN, Consejos, libro 739.

90 José María Calvo, Ramón fosé de Arce, Inquisidor General, Arzobispo de Zaragoza y líder de los afrancesados, Zaragoza, 2008, p. 436. Rafael OlAECHEA, Las relaciones... [ver n. 3], pp. 588-599.

91 AGS, Gf, leg. 326.

92 Si bien, en 1783, obtuvo una pensión de 1000 ducados sobre la mitra de Santiago de Compostela, y fue empleado por Francisco Antonio Lorenzana como juez sinodal del arzobispado de Toledo. AGS, Gf, leg. 326; libro 374, f. $15 \mathrm{r}^{\circ}$.

93 AGS, Gf, legs. 318, 323, 326. 
dente intra o extra estamental. La retirada del favor regio era, para ellos, una realidad desde hacía algunos años. Su proceso de apartamiento se completaría cuando, el 2 de noviembre de 1799, el rey enviara a los auditores regalistas, por medio del secretario de Estado, una aprobación explícita de su conducta frente al decreto, mientras que desaprobaba, también de forma explícita, la que habían mostrado los auditores más antiguos ${ }^{94}$. Éstos habían perdido contacto con el vértice decisorio y la opción que se perfilaba en su carrera, o al menos la permanencia en sus puestos, pasaba por establecer sus vínculos de fidelidad con el nuncio y, a través de éste, con la Santa Sede. En este sentido, resulta significativo que Juan Manuel Toubes pidiera repetidamente la jubilación, formalmente por motivos de salud, pero realmente por el duro enfrentamiento con Urquijo a causa de su oposición al decreto ${ }^{95}$. Le siguió Joaquín Palacín, quien en diciembre de 1799 también solicitó ser exonerado de su cargo, sin que aparentemente se terminara de apartar del tribunal ${ }^{96}$.

Si dibujáramos una línea temporal de la entrada de los auditores en el tribunal, de las mercedes regias obtenidas por cada uno de ellos o por sus parientes durante sus vidas, y de las fechas en las que fueron consultados por la Cámara de Castilla para ascensos, obtendríamos un gráfico elocuente: a la izquierda (fechas más alejadas de la controversia) se acumularían los acontecimientos referentes al ala que se mostró favorable a la Santa Sede. Los auditores de esta tendencia habrían perdido contacto con el entorno del rey años antes. En cambio, en el extremo derecho (fechas más recientes), tendríamos una acumulación de acontecimientos del ala regalista, que participaba de las relaciones que conducían al monarca, principal apoyo para su promoción, así como para la de los grupos sociales a los cuales pertenecían. El vínculo (o ausencia de éste) con la fuente de la gracia era el factor clave de la lealtad a una u otra opción en aquel contexto.

Las conclusiones que se desprenden de lo expuesto desbordan ampliamente lo eclesiástico; son parte de un fenómeno de mayores dimensiones. Y las implicaciones de nuestro planteamiento superan, creemos, el tema particular tratado, proponiendo una nueva forma de observar los enfrentamientos ideológicos:

94 Expediente [ver n. 30].

95 Rafael Olaechea. Las relaciones... [ver n. 3], p. 589-590. Constantino García, El Tribunal... [ver n. 10], pp. 94-95. AHN Estado, leg. 3440, exp. 7.

96 José María Calvo, Ramón fosé de Arce... [ver n. 90], p. 436. AHN, Estado, 3450, exp. 4. Renunció en 6 de agosto de 1814 y, en el expediente, no consta que fuera jubilado en una etapa anterior. 
1. Hemos tomado el conflicto en la Rota como ejemplo para exponer un proceso de concentración de poder en dos polos que se pretendían soberanos, lo que provocó la ruptura de un marco de doble fidelidad en el que el alto clero español había vivido hasta entonces. Partiendo de un conflicto preciso, hemos analizado dos importantes procesos paralelos de contornos difícilmente delimitables: la radicalización eclesiológica, por una parte, y la crisis del sistema político de la Monarquía basado en la economía de la gracia, por la otra.

2. En efecto, el punto cenital de ese doble proceso de acumulación de poder en instancias cada vez más excluyentes, que iban planteando la lealtad en términos crecientemente exclusivos, es difícilmente disociable de la agudización de la competencia por los recursos gestionados por la Corona y por el acceso a los puestos de influencia, que aún esta por estudiar en profundidad. La imposibilidad de integrar al conjunto de las élites por el reparto de las gracias que distribuía el monarca provocó la radicalización ideológica de los grupos concurrentes por el favor regio y una alteración del sistema de lealtades centrado en el rey.

3. El debate expuesto se engloba en uno de mayores dimensiones. Tanto en lo eclesiástico como en lo político, la cuestión de la autoridad, de su definición, se erigió en uno de los mayores problemas a finales del siglo XVIII. Saber quién dictaba o hablaba, en nombre de quién o de qué, con qué legitimidad, cuál era la última instancia de poder, o quién establecía lo que era verdad, constituyó una de las grandes cuestiones a $\operatorname{dirimir}^{97}$. El problema de la lealtad a una de las instancias en conflicto era también el problema del otorgamiento de la autoridad y de la legitimidad a una de ellas.

4. Con demasiada frecuencia la ruptura del alto clero con la sociedad política a finales del siglo XVIII se explica con recurso a la incompatibilidad apriorística de bloques coherentes de ideas. Hemos mostrado que, en realidad, es necesario reconstruir el contexto político del momento y analizar con detalle las experiencias previas de los actores que, en buena medida, explican su posicionamiento posterior. Las ideas no se baten impulsadas por nada más que por su fuerza interna, sino que son portadas por actores en contextos determinados.

97 Paola VISMARA, L'anti-infaillibilisme des jansénistes lombards à la fin du XVIIr siècle, en Sylvio DE FRANCESCHI (ed.), Le pontife et l'erreur. Anti-infaillibilisme catbolique et romanité ecclésiale aux temps post-tridentins (XVII ${ }^{e}-X X^{e}$ siècles), Lyon, 2010, pp. 89-90. 
